\title{
Transcatheter mitral valve chord repair
}

\author{
Vedran Savic ${ }^{1 \#}$, Alberto Pozzoli ${ }^{1 \#, ~ G o ̈ k h a n ~ G u ̈ l m e z ~}{ }^{1}$, Halil Demir ${ }^{1}$, Nikola Batinkov ${ }^{1}$, Shingo Kuwata ${ }^{1}$, \\ Alberto Weber ${ }^{2}$, Rolf Vogel $^{3}$, Felix Tanner ${ }^{1}$, Michel Zuber ${ }^{1}$, Francesco Maisano ${ }^{1}$, Maurizio Taramasso ${ }^{1}$ \\ ${ }^{1}$ Heart Valve Clinic, University Hospital of Zürich, University of Zürich, Zürich, Switzerland; ${ }^{2}$ Heart Surgery, HerzZentrum Hirslanden Zürich, \\ Zürich, Switzerland; ${ }^{3}$ Department of Cardiology, Bürgerspital Solothurn, Solothurn, Switzerland \\ \#These authors contributed equally to this work. \\ Correspondence to: Maurizio Taramasso. University Hospital of Zurich, Rämistrasse, 100 Zurich, Switzerland. Email: Maurizio.Taramasso@usz.ch.
}

\begin{abstract}
The field of mitral valve disease diagnosis and management is rapidly evolving. New understanding of pathophysiology and improvements in the adoption of sophisticated multimodality imaging modalities have led to early diagnosis and to more complex treatment. The most common cause of mitral regurgitation (MR) in the western world is in the primary alteration of the valve, which leads to degenerative leaflet prolapse due to chordal elongation or rupture and annular dilatation. Untreated, significant MR has a negative impact prognosis, leading to reduction of survival. In the setting of degenerative MR, surgical repair currently represents the standard of care. Treatment of asymptomatic patients with severe MR in the Valve Center of Excellence, in which successful repair reaches more than $95 \%$ and surgical mortality less than $1 \%$, symbolizes the direction for the next years. Transcatheter mitral valve repair with different devices, more recently the chordal replacement ones, is providing good outcomes and became a therapeutic option in highrisk patients with degenerative MR. In the future, more advances are expected from further development of interventional techniques, careful evaluation and better patient selection. This review will focus on long-term surgical outcomes of mitral valve repair with artificial chordae and on the emerging transcatheter chordal repair devices as therapeutic options for degenerative MR patients.
\end{abstract}

Keywords: Mitral valve (MV); transcatheter; chordal repair; mitral regurgitation (MR)

Submitted Feb 27, 2018. Accepted for publication Jul 27, 2018.

doi: 10.21037/acs.2018.09.09

View this article at: http://dx.doi.org/10.21037/acs.2018.09.09

\section{Introduction}

One of the most common valvular disorders is mitral regurgitation (MR), which has a prevalence of $2 \%$ in the general population and is present in $7 \%$ of the population 75 years of age or older $(1,2)$. The most frequent cause of MR in the developed countries is degenerative mitral valve (MV) disease, in which there is myxomatous degeneration of the MV leaflets, elongation and redundant chordal apparatus (3). Thickened redundant leaflets will prolapse back into the left atrium causing malcoaptation of leaflet edges and subsequent regurgitation (Figure 1). Rupture of chordae is not uncommon in older patients with MR, which will then cause a further increase in the severity of MR because of unsupported segments of the MV leaflets (Figure 2). Patients presenting with severe primary MR has a negative prognostic impact, which also decreases the survival (mortality rate more than 6.3\% per year compared with the expected survival rate) (4).

The current standard of care in this setting is surgical repair (1). Treatment of asymptomatic patients with severe MR in Valve Center of Excellence, in which successful repair reaches more than $95 \%$ and surgical mortality less than $1 \%$, represents the ideal setting to manage this disease in the next 5 years. Transcatheter MV devices for chordal replacement are emerging therapies with very satisfactory outcomes. Interventional techniques, better patient selection and intraoperative imaging guidance are certainly expected to advance in the near future. In this review, the primary focus will be on the surgical outcomes of chordal repair-as a conventional method of care-and transcatheter chordal repair as an alternative, equivalent therapeutic option. 


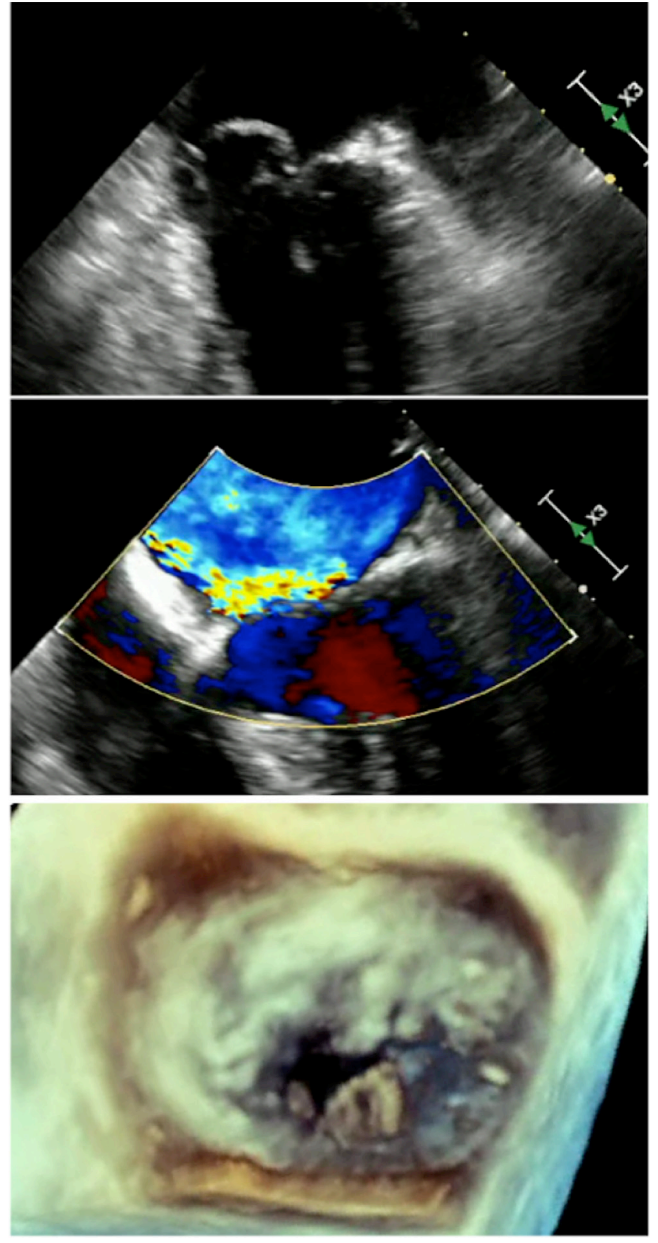

Figure 1 Echo view of a prolapse without flail of the posterior mitral leaflet (central segment). The three panels show, from top to bottom, the morphologic transoesophageal 2D echo aspect of a posterior prolapse, the color-Doppler analysis showing an eccentric jet causing severe regurgitation and a $3 \mathrm{D}$ en face view from the left atrium of the mitral leaflet (with the prolapse of $\mathrm{P} 2$ ).

\section{MV anatomy and prevalence of mitral leaflet prolapse}

The MV consists of two leaflets, separated by two commissures, a fibrous annulus, a subvalvular apparatus with chordae tendineae and two groups of papillary muscles attached to the left ventricle (5). The two leaflets are connected by chordae tendineae to the anterolateral and to the posteromedial papillary muscles. Three different types of chordae tendineae can be described: marginal or primary chordae (inserted into the free margin of the leaflets), basal or secondary chordae (insert near the annular attachment) and tertiary chordae (insert into the central part of the leaflets). The length of chordae regulates overall chordae tension, mitral haemodynamics and the coaptation area of the mitral leaflets. It has been shown that the chordae which are $10 \%$ longer than normal double the chordal tension, but do not make the MV incompetent, which proves that even minor changes in the length can have significant effects on the tension of the chordae.

The prevalence of mitral prolapse is $2-3 \%$ and its most common complication is MR (6). The most common etiology of mitral prolapse derives from the myxomatous degeneration, which is an intermediate form of disease which ranges from fibroelastic deficiency with limited prolapse, to more severe forms of multiple bileaflet prolapse with excessive tissue, such as Barlow's disease (7). A severe form is represented by leaflet flail, where no coaptation can be detected during systole. Most commonly, the posterior leaflet is affected by this condition and is associated with torn chordae, or even worse, ruptured papillary muscle.

\section{Preoperative and intraoperative imaging guidance}

Two-dimensional and Doppler echocardiography have become standard for the assessment of patients presenting with degenerative MR. Echocardiography is a diagnostic gold standard to identify mitral valve prolapse (MVP) with flail leaflet, determination of the severity of MR and planning. Transthoracic echocardiography (TTE) and transesophageal echocardiography (TEE) are complementary imaging methods, with the latter fundamental for intraprocedural guidance of these transcatheter chordal repairs. Heart multislice computed tomography (MSCT) and cardiac magnetic resonance imaging (MRI) offer complementary information during preoperative planning. MSCT is very useful for those therapies targeting the annulus, to evaluate annular structure and dimensions, quality and amount of annular tissue and its relationship with the left circumflex coronary artery. The MRI allows better visualization of the dynamic MV anatomy throughout the cardiac cycle, although it has no role during $\mathrm{MV}$ interventions. It has been proven to be a useful tool in both the preoperative and follow-up phase with a quantitative assessment of MR severity and its impact on left ventricular (LV) volumes and systolic function. In the near future, more sophisticated multimodality imaging software will shape and improve the management of transcatheter mitral repair therapies. 


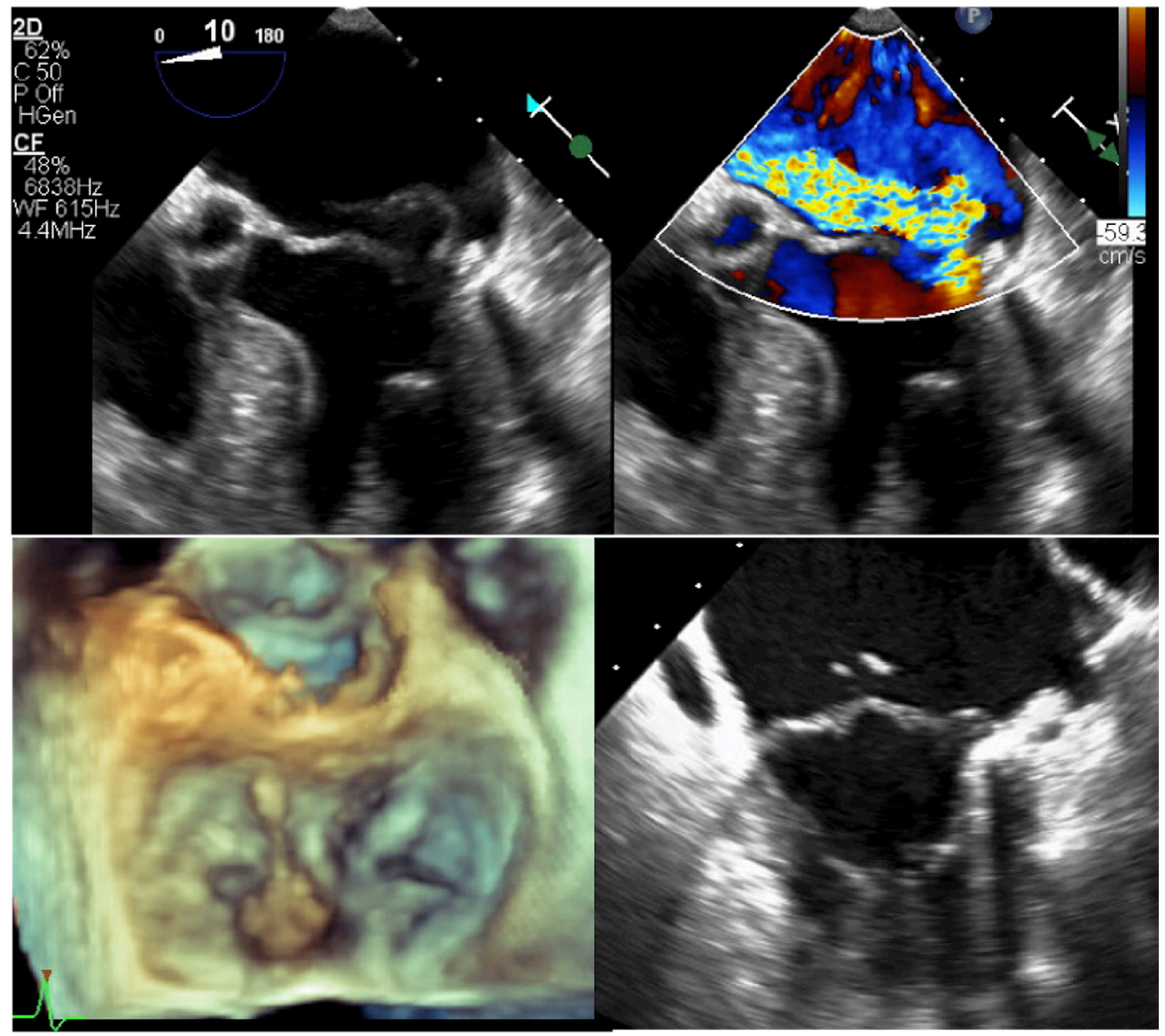

Figure 2 Transesophageal echo view of a prolapse with flail of the posterior mitral leaflet due to chordal rupture. The four-panel image depicts, from the top to the bottom and from left to right, the transoesophageal echo of the two mitral leaflets. Morphologic 2D with colorDoppler analysis show severe mitral regurgitation, with an eccentric jet. The 3D echo, en face view of the mitral leaflets, depicts the chordal rupture which is moving free in the left atrium during the systole. Last, the prolapse flail with bulging of the posterior leaflet in the central and medial segment can be appreciated in the $2 \mathrm{D}$ echo intercommissural morphologic view.

\section{Surgical outcomes}

Surgical repair is the preferred treatment for patients with primary MR and is associated with better outcomes than mitral replacement (8-10). MR can usually be repaired by either resection of the flail and prolapsing leaflet segment or by reconstructive techniques using artificial polytetrafluoroethylene (PTFE) chords (11). The techniques mainly adopted vary according to the center and the preference and/or experience of the surgeons, but the principal ones are the Von Oppel and Mohr's "loop technique", the simple chordae placement with atrial side knots and the David's multiple interdependent loop technique (12). Posterior leaflet prolapse is the most common pathology, causing severe MR and has higher success of durable repair than anterior leaflet disease or severe bileaflet disease (13). Artificial chordae with PTFE is a popular technique that can enhance the zone of coaptation of the MV when compared with leaflet resection, enhancing the valve performance. Currently, artificial chordae with PTFE is the technique perhaps the most adopted to correct anterior leaflet prolapse. Originally described by Frater and Zussa, this technique has grown in popularity over the past several years (14-17).

Artificial chordae insertion without leaflet resection can repair all prolapsing valves, independent of which leaflet is involved, and is ideal for minimally invasive approaches. One of the advantages of artificial chordae is 
their versatility, considering that chordae elongation is a major cause of MR in degenerative pathology. They can be applied to almost any pathology including systolic anterior motion (SAM), Barlow's disease, anterior and posterior mitral leaflet pathology, pediatric and adult populations, hypertrophic cardiomyopathy and others (12).

One the largest series of patients was described by Salvador, reporting an operative mortality of $<1 \%$ in a cohort of 608 patients undergoing MV repairs using artificial chordae. Survival was $84 \%$ at 15 years (16). Similar early mortality rates have been described by other series, ranging from $0 \%$ to $4.2 \%$. Perier et al. report a 10 year survival of $84 \%$ in a cohort of 225 patients following chordae implantation (15). These outcomes have been validated by comparison to classical techniques, in both children and adults and in robotic approaches. Falk et al. (18) compared Carpentier resection with artificial chordae insertion (using the "loop technique") for the repair of the MV (see later). Only 2 peri-operative deaths, both in the loop group, were reported, without late mortality. Seeburger $\mathrm{et} \mathrm{al}$. showed that there was $96.6 \%$ survival at 5 years in 317 patients undergoing artificial chordae loop insertion (11).

These results validated artificial chordae mortality outcomes as comparable with classical techniques in the long term (12). A seminal paper from David et al., reporting the results with PTFE chordae repair, showed that MV function remains stable in most patients during the first twenty years after operation. At 18 years follow-up, the freedom from reoperation on the MV was $90.2 \% \pm 2.4 \%$, the freedom from recurrent severe MR was $91.0 \% \pm 2.7 \%$, while the freedom from moderate or severe MR was $67.5 \% \pm 4.2 \%$. Cox regression analysis illustrated that isolated prolapse of the anterior leaflet was predictive of $\mathrm{MV}$ reoperation. Older age, hypertension and LV ejection fraction less than $40 \%$ were predictive of recurrent moderate or severe MR (19). Tabata et al. from Tokyo also reported the long-term results of their "tourniquet technique" chordal MV repair (700 patients with anterior, posterior and bileaflet prolapse). Again, the incidence of recurrent MR was higher in the anterior leaflet prolapse group, together with absence of an annuloplasty ring or band (20).

The biggest issue with chordal repair is adequate length determination and fixation during cardioplegic arrest, which can be particularly challenging on the anterior leaflet. The use of preformed, fixed-length chordae loops may be helpful in this regard. As a general rule, it is recommended that for posterior prolapse and chordal rupture, artificial chordae with a length of $12-14 \mathrm{~mm}$ are employed, while for the anterior leaflet their length should be $20-22 \mathrm{~mm}$.

Last, the development of artificial chordae techniques, accelerated in part due to their proposed applications in the setting of minimally invasive MV repair. In this setting, there is a large but mixed experience available in literature. Despite the heterogeneity of these studies, it is possible to conclude that the outcomes with artificial chordae implantation using minimally invasive approach offers the same risk and efficacy profile of conventional MV surgery (12).

\section{Transcatheter mitral chordal repair}

A great effort has been made in the development of catheter-based techniques for mitral chordae repair. This method applies all the basic steps of the conventional surgery on the beating-heart without the use of the cardiopulmonary bypass and follows the established doctrine of MV repair "respect rather than resect" (21). The first pioneering pre-clinical experiences of transcatheter neochordae implantation was performed by Maisano et al., in which delivery and adjustment of chordal length, after implantation, was done on the beating heart.

By using this feature, the surgeon could correct neochordal length under physiologic conditions, on the beating heart to reach prolapse correction $(22,23)$. Nowadays, there are three devices that enable transcatheter mitral chordae implantation. In terms of number of patients treated, the first and most known device is the NeoChord System (Neochord, Inc., Minnetonka, Minnesota), which received the CE Mark in 2013 and is based on a transapical approach. Second, the Harpoon Mitral Valve Repair System (H-MVRS, Harpoon Medical, Inc., Baltimore, MD, USA), which did not receive the CE Mark, but also works transapically. Finally, the ChordArt system (CoreMedic, Germany), which is based on a fully transcatheter approach (Table 1).

\section{NeoChord DS 1000 (Neochord, USA)}

NeoChord DS1000 is based on a solid surgical background and its catheter-based technique of implantation of neochordae presents an appealing treatment of degenerative MR (Figure 3). According to the mode of application, it is a minimally invasive system with adjustable PTFE sutures (24-26). It is implanted through a small incision on the beating heart with the transapical approach. The procedure is carried out under echocardiographic guidance. An anchor is placed on the leaflet on one side and on the LV 


\begin{tabular}{|c|c|c|c|c|}
\hline \multirow[t]{3}{*}{$\begin{array}{l}\text { NeoChord } \\
\text { System }\end{array}$} & Minimally invasive system & $\begin{array}{l}\text { Complexity of the lesion is } \\
\text { affecting the reduction of MR } \\
\text { and outcomes }\end{array}$ & TACT trial & 30 patients at 7 centers \\
\hline & $\begin{array}{l}\text { Implantation without the use } \\
\text { of CPB }\end{array}$ & $\begin{array}{l}\text { Residual leaflet prolapse in } \\
\text { complex anatomy }\end{array}$ & $\begin{array}{l}\text { Multicenter, } \\
\text { nonrandomized, } \\
\text { prospective study }\end{array}$ & $\begin{array}{l}\text { At } 30 \text { days, } 17 \text { patients } \\
(59 \%) \text { achieved MR grade } \\
\leq 2+0.36\end{array}$ \\
\hline & $\begin{array}{l}\text { Is carried out under } \\
\text { echocardiographic guidance }\end{array}$ & Long learning curve & & $\begin{array}{l}\text { More than } 500 \text { patients } \\
\text { treated worldwide }\end{array}$ \\
\hline \multirow[t]{2}{*}{$\begin{array}{l}\text { Harpoon Mitral Valve } \\
\text { Repair System }\end{array}$} & $\begin{array}{l}\text { Leaflet anchoring is carried } \\
\text { out with a preformed knot } \\
\text { instead of free-edge leaflet } \\
\text { fixation }\end{array}$ & $\begin{array}{l}\text { Fixation of the neochord far from } \\
\text { the free edge of the leaflet }\end{array}$ & TRACER trial & 30 patients at 6 centers \\
\hline & & & & $\begin{array}{l}\text { At } 6 \text { months in } 85 \% \text { of } \\
\text { patients, mild MR was } \\
\text { stable }\end{array}$ \\
\hline \multirow[t]{2}{*}{ ChordArt } & $\begin{array}{l}\text { Implantation of premeasured } \\
\text { neochordae }\end{array}$ & $\begin{array}{l}\text { Residual leaflet prolapse in } \\
\text { complex anatomy }\end{array}$ & CHAGALL trial & - \\
\hline & $\begin{array}{l}\text { Simple anchoring system, } \\
\text { with which the distal chord } \\
\text { is applied in its anatomical } \\
\text { position, directly to the } \\
\text { papillary muscle }\end{array}$ & $\begin{array}{l}\text { Complexity of the lesion is } \\
\text { affecting the reduction of MR } \\
\text { and outcomes }\end{array}$ & $\begin{array}{l}\text { Multi-center, } \\
\text { nonrandomized, } \\
\text { prospective study }\end{array}$ & \\
\hline
\end{tabular}

CPB, cardiopulmonary bypass; MR, mitral regurgitation; LV, left ventricular.

Reloadable Suture Cartridges

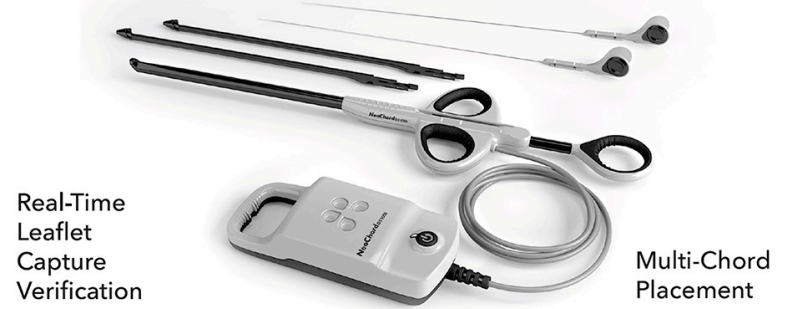

Figure 3 The NeoChord DS 1000 System_ Courtesy of NeoChord (NeoChord, USA).

myocardium on the other side. Neochordae is then secured under the proper tension in order to adjust the artificial chordal length. The device obtained the CE Mark in 2012, after the initial results were reported in the feasibility TACT trial, where an overall reduction of $M R$ to $\leq 2+$ in
86.7\% among 30 patients has been described. So far, the device has been used in nearly 1,000 patients.

A multicenter study conducted in Europe showed excellent results with the reduction of MR to mild or less residual in $96.7 \%$ of patients who received $\geq 2$ neochordae. Further, a 98\% survival at 1-year follow-up and $84 \%$ freedom from major cardiac adverse events were observed (26). The complexity of the lesion is clearly affecting the reduction of MR. For example, a treatment of isolated P2 segment flail or prolapse with NeoChord DS 1000, 1-year freedom from MR recurrence, mitral surgery, mortality, rehospitalisation and stroke was 94\%. However, in the presence of more complex anatomy (bileaflet or commissural involvement) or treatment of multiple posterior leaflet segments with prolapse or flail freedom from the composite endpoint was $63 \%$ and $82 \%$, respectively. There has also been a learning curve effect 
observed (24).

As the approach with NeoChord is becoming more appealing, a need for a better patient selection has arisen and even the patients in early stages of MR without annulus dilatation have become appropriate candidates for this type of the intervention (27).

There is currently an ongoing clinical investigation of NeoChord in a randomized trial in the United States, "Randomized trial of the NeoChord DS1000 system versus open surgical repair" (RECHORD). The greatest limitations of the current generation of the device lies in its transapical access. The device requires multiple entries and exits through the apex and is delivered sheathless. In the treatment of multi-segment disease, or when there is a need for multiple chordae, there is also an increased risk of bleeding. Nevertheless, NeoChord implantation has been shown as a safe and feasible procedure that

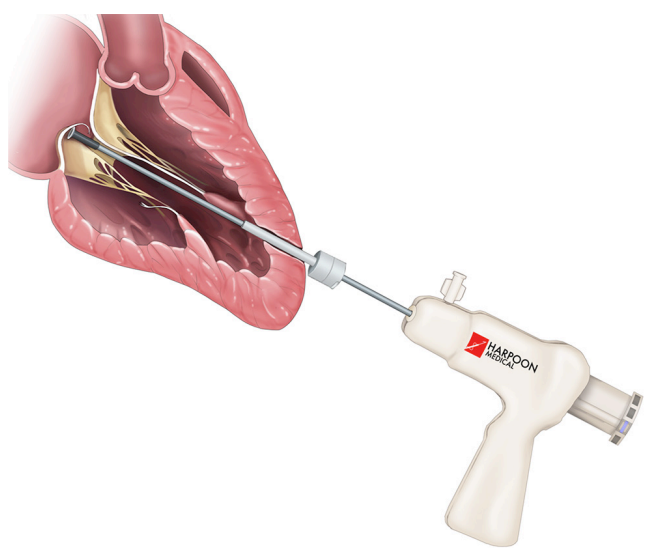

Figure 4 The Harpoon TSD-5 System_ Courtesy of Harpoon (Edwards Lifescience, USA). shortens the time of operation in comparison to open-heart MV repair.

\section{Harpoon TSD-5 (Edwards Lifescience, USA)}

In an early feasibility trial in patients with degenerative MR and posterior leaflet prolapse, the Harpoon device has been investigated (28). The Harpoon TSD-5 (Edwards Lifesciences, Irvine, USA) device is a $14 \mathrm{~F}$ system designed for transapical multiple PTFE implantation. Unlike the NeoChord procedure, where the surgical approach is rather lateral, the apex is reached through a more anterior incision, and the device is inserted into the ventricle more closely to the left anterior descending coronary artery. Selection of the entry site of the left ventricle and navigation towards the MV apparatus is performed using a biplane view at mid-commissural and long-axis views. After identification of the target site on the prolapsing leaflet, the device is stabilized by applying gentle pressure on the ventricular side of the leaflet with the end effector. Further confirmation of the correct position of the device can be obtained using the 3D view from both ventricular and atrial sides, adopting different levels of ultrasound depth that are represented by specific colors. At this point, the device is activated by pushing the handle fire button and a specially designed 21-gauge needle wrapped with 50 coils of ePTFE in a preformed knot configuration perforates the leaflet (Figures 4,5). After needle retrieval, a double-helix ePTFE knot is formed on the atrial side of the leaflet, securing the associated pair of artificial ePTFE chords to the leaflet. The major difference from the NeoChord is in the mechanism of leaflet engagement. What should be investigated at long-
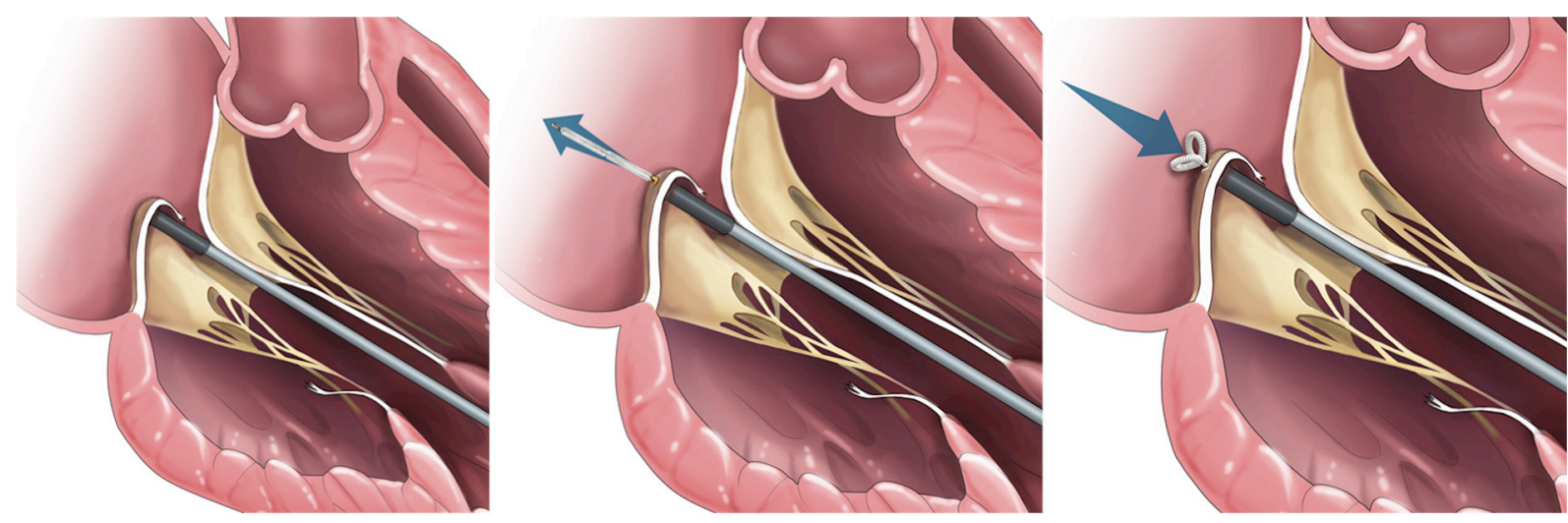

Figure 5 The Harpoon TSD-5 System during the different phases of the chordal implantation_ Courtesy of Harpoon (Edwards Lifescience, USA). 

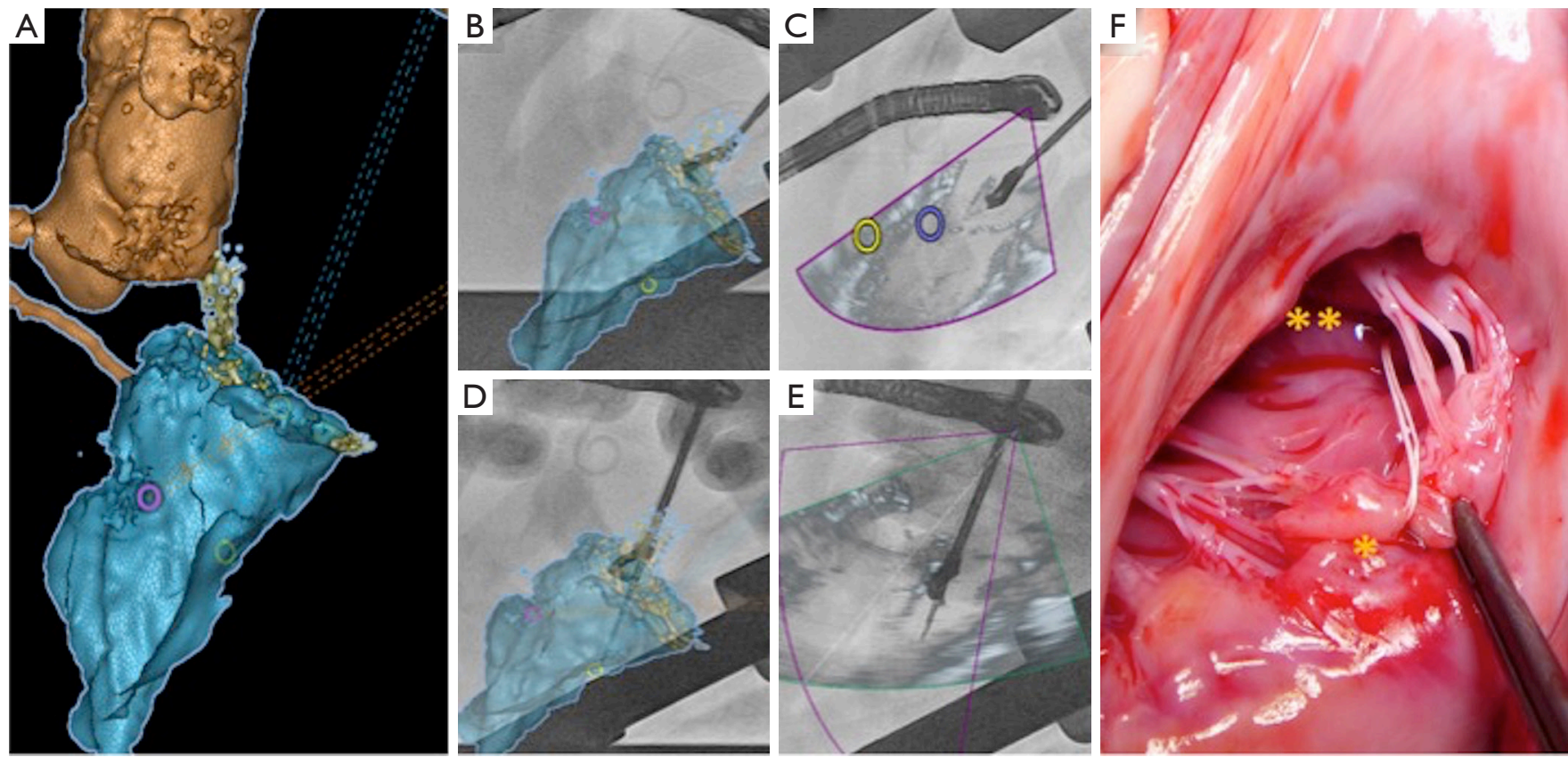

Figure 6 Intraprocedural guidance with multimodality fusion imaging during preclinical experience with Chordart device, using the EchoNavigator ${ }^{\circledR}$-system (Philips Healthcare, Best, The Netherlands) side-by-side with the HeartNavigator ${ }^{\circledR}$-system (Philips Healthcare), which enables CT planning and CT-fluoroscopy overlay. Using the HeartNavigator, the optimal trajectory of the device from the tip of the target papillary muscles through the corresponding MV leaflet, to define the coaxial entry point into the left atrium, was assessed (A). Grasping of P2 segment with HeartNavigator (B), EchoNavigator (C) and TEE guidance in real-time. Finally, Chordart implant with HeartNavigator (D) and EchoNavigator (E) guidance [F; Leaflet side of Chordart ${ }^{*}$ ) papillary muscle side of Chordart $\left(^{* *}\right)$ ]. MV, mitral valve; CT, computed tomography; TEE, transesophageal echocardiography.

term follow-up should be the fixation of chordae far from the free edge of the leaflet.

The results of the initial feasibility trial evaluating Harpoon TSD-5 device showed that among 30 patients, 3 patients required conversion to open mitral surgery. Neither major adverse events nor deaths occurred during the study. At 1 month in 24 out of 27 patients (89\%), MR was mild or even smaller and in three out off 27 patients (11\%), moderate. At 6 months, MR was mild or smaller in 22 out of 26 patients (85\%), moderate in two out of 26 patients (8\%) and severe in two out of 26 patients (8\%). During the investigation at 6 months, favourable cardiac remodeling, decrease of LV and left atrial (LA) volumes and as well as mitral annulus diameter reduction were reported (28).

Crucial patient selection is the critical point to both chordal implantation devices. Preferable pathology of the MV for a successful and durable repair is a mono-segmental pathology, limited LV dilatation and without or with mild annular dilatation. Furthermore, what is different from the surgical chordal repair is that the distal extremity of the PTFE suture is not fixed to the papillary muscles, as in native anatomy, but it is fixed to the apical access. The consequences of this should be investigated at long-term follow-up.

\section{ChordArt (CoreMedic, Germany)}

The ChordArt System has been designed to implant premeasured neochordae in order to overcome some of the limitations of the previously mentioned devices. Transatrial or transseptal antegrade approaches are used to place the neochordae. The anchoring system is simple, with which the distal chord is applied in its anatomical position, directly to the papillary muscle. For this type of therapy, multimodality imaging guidance could theoretically play a central role, integrating echo- and computed tomography-fluoro fusion imaging to determine trajectories and orientation (Figure 6). With preoperative echo or with CT, the size of the 


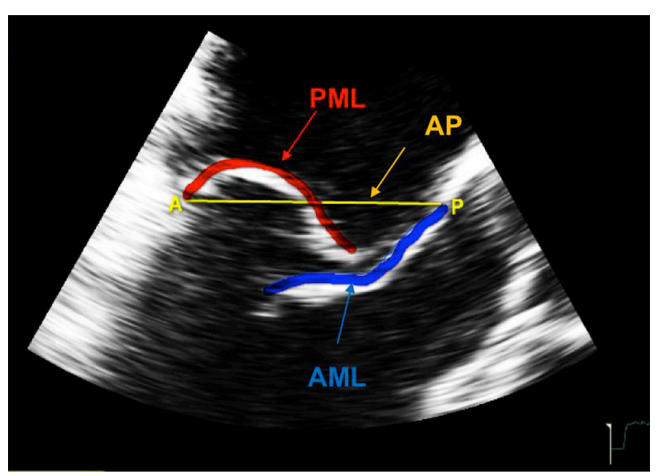

Figure 7 Leaflet-to-Annulus Index $<1.4$, defined as the ratio between the sum of anterior leaflet length and posterior leaflet length over antero-posterior length, can be used as reliable predictor to identify patients without annular dilatation. Courtesy of NeoChord (NeoChord, USA) (30,31). AML, anterior mitral leaflet; PML, posterior mitral leaflet; AP, antero-posterior diameter.

implant can be determined. Preclinical validation has been done and first-in-human implants with surgical direct implantation of the device has been recently announced, reporting good outcomes (29). The Chagall trial will be the prospective, multicenter study which will establish the safety and the effectiveness of the Chordart system (30).

\section{Role of concomitant annuloplasty to artificial chordae}

The progress of transcatheter therapies and in particular, of the implantation of mitral chordae, is constant and in continuous evolution. The major limitation lies in the absence of combined treatment of mitral annulus dilatation, a condition associated in most patients with degenerative mitral pathology. The surgical results of mitral repair without annuloplasty are unsatisfactory in the long term and the initial experience with NeoChord also disadvantages the latter subgroup (26,31). A critical factor is therefore the selection and early treatment of the patient in a phase of disease in which prolapse and/or flail is still the prevalent pathology, whilst in the absence or near-annular dilation. Nowadays, early referral allows treating patients with only leaflet disease and preserved $L V$ volumes and not dilated annuluses, questioning the need for a ring and confirming the rationale behind the transcatheter chordal repair alone.

The Leaflet-to-Annulus Index (LAI) $<1.4$, defined as the ratio between the sum of anterior leaflet length and posterior leaflet length over antero-posterior length, can be used as reliable predictor to identify patients without annular dilatation $(32,33)$. The LAI identifies the quantity of overlapping leaflet tissue that will represent the potential coaptation surface after the correction (Figure 7). This excess of leaflet tissue will constitute the potential coaptation surface after an effective restoration of the posterior leaflet movement, e.g., using the NeoChord repair system. In the near future, with increasing clinical evidence, improvements in multimodality imaging guidance and clearer indications, it will be conceivable to combine in most cases the treatment of leaflets (e.g., chordae, edge to edge) with direct mitral annuloplasty, whenever the latter is needed (34).

\section{Conclusions}

In primary MR, surgical repair with artificial chordae, often through a minimally invasive approach, provides excellent outcomes. Transcatheter mitral chordal devices enabled targeted and less invasive repair, providing promising initial results. These therapies have the potential to simplify and increase the quality and rates of mitral repair and decrease the morbidity associated with conventional open cardiac mitral operations. As these devices are in the early phases of clinical experience, further investigation with longerterm follow-up and direct comparison with conventional MV surgery is necessary to validate the role of transcatheter chordae in the armamentarium of multidisciplinary valveMV therapies.

\section{Acknowledgements}

None.

\section{Footnote}

Conflicts of Interest: The authors have no conflicts of interest to declare.

\section{References}

1. Baumgartner H, Falk V, Bax JJ, et al. 2017 ESC/EACTS Guidelines for the management of valvular heart disease. Eur Heart J 2017;38:2739-91.

2. Mirabel M, Iung B, Baron G, et al. What are the characteristics of patients with severe, symptomatic, mitral regurgitation who are denied surgery? Eur Heart J 
2007;28:1358-65.

3. Olson LJ, Subramanian R, Ackermann DM, et al. Surgical pathology of the mitral valve: a study of 712 cases spanning 21 years. Mayo Clin Proc 1987;62:22-34.

4. Carabello BA. Mitral regurgation: basic pathophysiologic principles. Mod Concepts Cardiovasc Dis 1988;57:53-8.

5. Taramasso M, Pozzoli A, Basso C, et al. Compare and contrast tricuspid and mitral valve anatomy: interventional perspectives for transcatheter tricuspid valve therapies. EuroIntervention 2018;13:1889-98.

6. Delling FN, Vasan RS. Epidemiology and pathophysiology of mitral valve prolapse: new insights into disease progression, genetics and molecular basis. Circulation 2014;129:2158-70.

7. Adams DH, Rosenhek R, Falk V. Degenerative mitral valve regurgitation: best practice revolution. Eur Heart J 2010;31:1958-66.

8. Enriquez-Sarano M, Schaff HV, Orszulak TA, et al. Valve repair improves the outcome of surgery for mitral regurgitation. A multivariate analysis. Circulation 1995;91:1022-8.

9. Jokinen JJ, Hippelainen MJ, Pitkanen OA, et al. Mitral valve replacement versus repair: propensity-adjusted survival and quality-of-life analysis. Ann Thorac Surg 2007;84:451-8.

10. Moss RR, Humphries KH, Gao M, et al. Outcome of mitral valve repair or replacement: a comparison by propensity score analysis. Circulation 2003;108 Suppl 1:II90-7.

11. Seeburger J, Falk V, Borger MA, et al. Chordae replacement versus resection for repair of isolated posterior mitral leafl et prolapse: a egalite. Ann Thorac Surg 2009;87:1715-20.

12. Ibrahim M, Rao C, Savvopoulou M, et al. Outcomes of mitral valve repair using artificial chordae. Eur J Cardiothorac Surg 2014;45:593-601.

13. Suri RM, Clavel MA, Schaff HV, et al. Effect of recurrent mitral regurgitation following degenerative mitral valve repair: long-term analysis of competing outcomes. J Am Coll Cardiol 2016;67:488-98.

14. Frater RW, Vetter HO, Zussa C, et al. Chordal replacement in mitral valve repair. Circulation 1990;82:IV125-30.

15. Perier P, Hohenberger W, Lakew F, et al. Toward a new paradigm for the reconstruction of posterior leaflet prolapse: midterm results of the "respect rather than resect" approach. Ann Thorac Surg 2008;86:718-25; discussion 718-25.
16. Salvador L, Mirone S, Bianchini R, et al. A 20-year experience with mitral valve repair with artificial chordae in 608 patients. J Thorac Cardiovasc Surg 2008;135:1280-7.

17. Padala M, Powell SN, Croft LR, et al. Mitral valve hemodynamics after repair of acute posterior leaflet prolapse: quadrangular resection versus triangular resection versus neochordoplasty. J Thorac Cardiovasc Surg 2009;138:309-15.

18. Falk V, Seeburger J, Czesla M, et al. How does the use of polytetrafluoroethylene neochordae for posterior mitral valve prolapse (loop technique) compare with leaflet resection? A prospective randomized trial. J Thorac Cardiovasc Surg 2008;136:1205; discussion 1205-6.

19. David TE, Armstrong S, Ivanov J. Chordal replacement with polytetrafluoroethylene sutures for mitral valve repair: a 25-year experience. J Thorac Cardiovasc Surg 2013;145:1563-9.

20. Tabata M, Kasegawa H, Fukui T, et al. Long-term outcomes of artificial chordal replacement with tourniquet technique in mitral valve repair: a single-center experience of 700 cases. J Thorac Cardiovasc Surg 2014;148:20332038.e1.

21. Espiritu D, Onohara D, Kalra K, et al. transcatheter mitral valve repair therapies: evolution, status and challenges. Ann Biomed Eng 2017;45:332-59.

22. Maisano F, Cioni M, Seeburger J, et al. Beatingheart implantation of adjustable length mitral valve chordae:acute and chronic experience in an animal model. Eur J Cardiothorac Surg 2011;40:840-7.

23. Maisano F, Michev I, Rowe S, et al. Transapical endovascular implantation of neochordae using a suction and suture device. Eur J Cardiothorac Surg 2009;36:118-22.

24. Seeburger J, Rinaldi M, Nielsen SL, et al. Off-pump transapical implantation of artificial neo-chordae to correct mitral regurgitation: the TACT Trial (Transapical Artificial Chordae Tendinae) proof of concept. J Am Coll Cardiol 2014;63:914-9.

25. Colli A, Bagozzi L, Banchelli F, et al. Learning curve analysis of transapical NeoChord mitral valve repair. Eur J Cardiothorac Surg 2018;54:273-80.

26. Colli A, Manzan E, Aidietis A, et al. An early European experience with transapical off-pump mitral valve repair with NeoChord implantation. Eur J Cardiothorac Surg 2018;54:460-6.

27. Suri RM, Vanoverschelde JL, Grigioni F, et al. Association between early surgical intervention vs watchful waiting and outcomes for mitral regurgitation due to flail mitral valve leaflets. JAMA 2013;310:609-16. 
28. Gammie JS, Bartus K, Gackowski A, et al. BeatingHeart Mitral Valve Repair Using a Novel ePTFE Cordal Implantation Device: A Prospective Trial. J Am Coll Cardiol 2018;71:25-36.

29. First patient treated in first-in-man study of ChordArt mitral valve repair system. Available online: https:// cardiovascularnews.com/first-patient-treated-in-first-inman-study-of-chordart-mitral-valve-repair-system

30. Weber A. Changing the Way of Treating Mitral Valve Prolapse: A Sutureless Neochordal Replacement. TCT 2016, Washington. Available online: https://www.tctmd. com/slide/changing-way-treating-mitral-valve-prolapsesutureless-neochordal-replacement

31. De Bonis M, Lapenna E, Maisano F, et al. Long-term results ( $\leq 18$ years) of the edge-to-edge mitral valve repair without annuloplasty in degenerative mitral regurgitation: implications for the percutaneous approach. Circulation

Cite this article as: Savic V, Pozzoli A, Gülmez G, Demir H, Batinkov N, Kuwata S, Weber A, Vogel R, Tanner F, Zuber M, Maisano F, Taramasso M. Transcatheter mitral valve chord repair. Ann Cardiothorac Surg 2018;7(6):731-740. doi: 10.21037/acs.2018.09.09
2014;130:S19-24.

32. Maisano F, La Canna G, Grimaldi A, et al. Annular-toleaflet mismatch and the need for reductive annuloplasty in patients undergoing mitral repair for chronic mitral regurgitation due to mitral valve prolapse. Am J Cardiol 2007;99:1434-9.

33. Colli A, Besola L, Montagner M, et al. Prognostic impact of leaflet-to-annulus index in patients treated with transapical off-pump echo-guided mitral valve repair with NeoChord implantation. Int J Cardiol 2018;257:235-7.

34. von Bardeleben RS, Colli A, Schulz E, et al. First in human transcatheter COMBO mitral valve repair with direct ring annuloplasty and neochord leaflet implantation to treat degenerative mitral regurgitation: feasibility of the simultaneous toolbox concept guided by $3 \mathrm{D}$ echo and computed tomography fusion imaging. Eur Heart J 2018;39:1314-5. 